Birgitta Svensson*

\title{
The construction of semantic waves of knowledge-building: High school students' natural science writing
}

\begin{abstract}
This paper investigates popular science articles written by Swedish high school students as part of a project aimed at building their knowledge of the content of their natural science curriculum by integrating it with their Swedish language studies. This work, an effort to promote content-area literacy and knowledge-building, was undertaken during their project time. By analyzing the students' texts, the purpose of the study was to access their value as knowledge-building tools. The analysis of the texts was carried out utilizing Maton's (2013) theoretical concepts of waves of semantic density and semantic gravity, which are seen as a prerequisite for cumulative knowledge-building. The investigation extends previous studies on semantic waves since it incorporates into the analyses both linguistic features and visual elements. The students were writing in pairs and a total of six texts were analyzed. The text analyses showed three different types of semantic profiles, with four of the texts including features that served as means of cumulative knowledge-building. In a concluding section, some pedagogical implications of the study are considered.
\end{abstract}

\section{Keywords}

knowledge-building; semantic density; semantic gravity; content area literacy; writing to learn

\section{Introduction}

This study explores content area literacy and how writing is used as a knowledge-building tool by a secondary school teaching team, at a high school located on the West Coast of Sweden, here referred to as the T-unit. At the T-unit, subject-integration between language study and the natural sciences during so-called project time (4 hours/week) was carried out. The natural science curriculum provided the content and the language activities were used as a means of communication and a learning tool. At Swedish high schools, the natural science program is considered the most difficult, and project time was launched as a way of counteracting the increasing number of students dropping out of the program. The instructional design was based upon the premise that students drop out of the natural sciences program not only because of the complexity of the scientific content, but also because of the complexity of the language through which that content is conveyed: highly condensed sentences, replete with technical terminology and abstractions, embedded in clause structures that are rare in normal, everyday conversations and prose (Halliday 1998; Schleppegrell 2004; Veel 1997). As we will see in section 4, the T-unit teachers decided to implement a program guided by four, partially overlapping, pedagogical principles: (1) studentcentered learning with multiple collaborative activities; (2) the bridging of in and out of school experiences; (3) the view of communication as a social act, and (4) as a means of learning. The model proved a success: more students succeeded in getting through the natural science program and, in addition, a higher number of students passed the national language test with distinction.

\footnotetext{
* Birgitta Svensson

E-mail: birgitta.svensson@gu.se

Department of pedagogical, curricular and professional studies

University of Gothenburg
} 


\section{Purpose}

The aim of this study is to examine how effective the texts produced by the T-unit students are as knowledge-building devices, a purpose often neglected in the research on content area literacy (Martínez et al. 2015; Newell 2006). To this end, I examine six texts using Maton's (2013) concept of semantic waves (including waves of semantic density and semantic gravity), however, extended to incorporate not only verbal, but also visual elements.

\section{Theoretical background}

Below, I will focus on previous linguistic research, which is of value to my study.

\subsection{Writing to learn}

The effectiveness of writing as a learning tool has been demonstrated in numerous studies on content area literacy (e.g. Applebee 1996; Dyson 1997; Gallas 1994; Langer 1992; Langer/Applebee 1987; Newell 2006; Nystrand/Duffy 2003; Ulusoy/Dedeoglu 2011; Troia/Graham 2003; Vacca/ Vacca 2000). However, writing studies have also shown that different writing tasks lead to different types of learning. Writing answers to questions or summarizing various sections of a text may give the students a certain, although somewhat superficial, understanding of a topic. The type of writing assignments that stimulate the greatest in-depth learning are those that require the students to analyze, interpret or synthetize information from multiple sources. This should be seen in light of the various complex cognitive challenges that the manipulation, synthesis and modulation of various compositional strategies place on the writer. Thus, writing an essay is a complex activity which challenges the student's cognition in far more profound ways than, for example, the writing of a description, which is more likely to lead to superficial learning. Also, an essay is a text that requires synthesis, i.e. the comprehension and incorporation of information from multiple sources, and requires as well the alternation between reading and writing activities. In addition, a synthesis text incorporates information from multiple sources, and requires the student to alternate between reading and writing activities. Such a hybrid task has been shown to be an effective learning tool since it involves students in recursive processes of selecting and organizing content and connecting it with their prior knowledge (Applebee 1996; Martínez et al. 2015; Newell 2006).

\subsection{Knowledge-building and specialized language}

Legitimation Code Theory (LCT) is a theoretical framework and a tool for the analysis of knowledge construction in various cultural fields, particularly education. It builds on the work of Bernstein (1996) and Morais et al. (2001), who distinguish between three fields within any academic discourse. One field is production of new knowledge, which takes place at universities and research labs. A second field is reproduction, which occurs in schools where novices are tasked with acquiring the knowledge produced within the aforementioned academic contexts in order to prepare themselves for a professional career. A third field is that of recontextualization, which is implemented by the National Boards of Education and by text-book writers. Here, knowledge produced in the first field (at universities and research laboratories) is subjected to review and selection regarding what should be included in school curricula (the second field) and thus will be retained and reproduced.

Systemic functional linguistics is a highly effective tool in demonstrating how language use varies according to subject area (Christie/Drewianka 2008; Coffin 2006; Fang et al. 2006). In systemic functional linguistics, written language development is viewed as a movement from a congruent grammar and everyday lexis, displaying commonsense knowledge, to an increasingly more non-congruent grammar with an abstract and technical vocabulary, expressing un-commonsense knowledge (e.g. Christie/Derewianka 2008; Colombi 2006; Halliday 1998; Martin/Rose 2008; Schleppegrell 2004; Veel 1997). Halliday (1993: 103-122) has defined the use of grammatical metaphors as the single most important phenomenon in non-congruent language use, accom- 
plishing both a linguistic condensation and an objectification of the content. According to Halliday (1998), nominalization is central in the construction of grammatical metaphors, whereby, for example, a process (which is congruently realized by a verb) comes to be encoded in a noun instead (e.g. remove - removal). Thus, the use of grammatical metaphor involves a metaphorical shift in the grammatical class. Nominalization is a common linguistic feature of the academic register, and not least so in the registers governing the natural science discourse (Halliday 1998: 196f.).

Combining the two theoretical frameworks, Legitimation Code Theory (Bernstein 1996; Morais et al. 2001), and systemic functional linguistics, Maton (2009, 2011, 2013) and Macnaught et al. (2013) have analyzed the underlying principles of knowledge-building in various disciplines and in student writing. In this study, I will apply Maton's theoretical concepts of semantic density (SD), semantic gravity (SG), and sematic waves, which have already been used in several studies focusing on learning constraints and possibilities in educational settings (see e.g. Christie/ Macken-Horarik 2011; Kilpert/Shay 2013). Semantic density refers to the presentation of meaning in highly condensed form. Maton (2013) visualizes the degree of condensation as a continuum ranging from stronger semantic density $(\mathrm{SD}+$ ), which is most often accomplished through the use of grammatical metaphors, to weaker semantic density (SD-). Research articles exhibit strong semantic density, with a concentration of highly technical words and grammatical metaphors, whereas school text books have a lower degree of semantic density, with fewer abstractions and nominalizations. The theoretical concept of semantic gravity refers to the degree to which meaning is context-dependent. In general, meaning relates to a context, but, in academic registers, the high degree of specialization provides a weaker semantic gravity (SG-). Conversely, classroom discourse, in which technical concepts are often contextualized, gives evidence of a stronger semantic gravity $(\mathrm{SG}+)$.

As a way of demonstrating how all practices incorporate a dynamicity of semantic density and semantic gravity, Maton (2013) introduces the concept semantic waves, illustrating upward and downward movements in a text. A downward shift represents ways of unpacking and contextualizing technical concepts (SD-; SG+), whereas an upward movement represents ways of repacking and decontextualizing more commonsense knowledge, a shift that is accompanied by a noncongruent language use (SD+; SG-). In classroom discourse, both movements play an important role. The downward move builds a bridge between the often highly condensed and abstract meaning of a text and the students' everyday language and commonsense experiences. But of equal importance is the repacking of meaning, that is, the upward shift, which enables the students to meet what Macnaught et al. (2013) refer to as power words (technical concepts) and power grammar (non-congruent language/grammatical metaphors). According to Maton (2009, 2013), this repacking is a prerequisite for the students' engagement in cumulative knowledge-building, that is, a learning process in which new knowledge is integrated with old knowledge. This, in turn, is a prerequisite for students' successful participation in higher education and their ability to pursue lifelong learning, a skill that is crucial in today's ever-changing information and technology society. In contrast, and as a consequence of the students not unpacking the information, segmented learning occurs. This implies that isolated units of knowledge are simply added to each other. This mere accumulation of knowledge masks its interrelatedness, thus preventing the students from making any connections between what they already know and new information (Maton 2013).

As for communication within the natural science, it takes place not only in verbal language. Rather, natural science texts are semiotic hybrids (Lemke 1998: 87), consisting of a blend of verbal texts, mathematical expressions, and various visual-graphical representations (such as tables, graphs, diagrams, drawings, and photos). Overall, multimodality plays a significant role in the ways we construe meaning of contemporary society (Lemke 2003; Kress/van Leeuwen 1996; Macken-Horarik 2004; O'Halloran 2005; Whittaker et al. 2007). In education, there is a continuous need to enable the students to understand both the affordances and constraints of semi- 
otic resources as well as how they interact in various texts (Bezemer/Kress 2008; Maun/Myhill 2008). Over the past decades, a large body of research studies on multimodality in school-based settings has been produced. In these studies, both multimodal textbooks and the students' use of semiotic resources in their text production (such as images and videos) has been examined (Jones 2007; Kress et al. 2001; O'Halloran 2007; Unsworth 2001). Several of these investigations target younger students. However, none of them consider the ways in which semiotic resources are used in combination with verbal texts in a way that underpins knowledge-building activities in content area literacy at the high school level. This will be a secondary aim of the current study.

\subsection{Learning as a socially situated activity}

Language activities, including writing, do not occur in a vacuum, but are influenced by a number of contextual variables (e.g., writing assignment, instruction, view of learning and language development, type of feedback and assessment, and the interaction between students and between teacher and student). This study is grounded in a cognitive and social constructivist perspective, which, while acknowledging how the learner gradually appropriate knowledge in more refined ways, also views learning as taking place through participation in social activities (Barton et al. 2000; Crawford et al. 2000; Richardson 2003). One aspect of this approach is Rogoff's (1990) cognitive apprenticeship theory, which postulates how a teacher or a more knowledgeable peer may support the learner's development through various mediating tools (e.g., writing and speaking). This is, in part, influenced by Vygotsky's (1978) zone of proximal development metaphor in which social interaction and collaborative processes (between students and between teacher and students) are a prerequisite for students' continual advancement.

In the constructivist framework, higher-order intellectual activities and authentic-like situations for learning are favored. In this way, the students become participants in what Lave/Wenger (1991) and Wenger (1998) refer to as communities of practice. This participation may foster a collective competence (Wenger 1998), including similar ways of solving problems, speaking, writing, and acting. Thus, learning is considered socially situated, and the texts produced in these contexts are seen as part of discourses that are made up of "distinctive ways of using language, other symbols, thinking, believing, acting, interacting, gesturing, and dressing" (Gee 1992: 160). Student-centred learning involves a dialogical classroom where the voices of the students play a crucial role and where students' texts are looked upon as important knowledge resources (Nystrand 1997). The ambition of the T-unit's teachers is thus to establish a community of practice that, through the students' collaboration and sharing of learning strategies, including the practice of writing to learn, will enable the students to master the natural science curriculum.

\section{Communication as a social act and learning tool}

All T-unit teachers agree that, in order for students to become skilled writers, they need to understand that writing is a social act of communication and, thus, in their text production, they need to incorporate an awareness of their readers' age, educational level, culture, and so forth. This combined emphasis on communication and reader awareness is no doubt the single most important aspect of writing (and speech) instruction in the project classroom. Writing as a social activity is extensively practiced in many classroom situations, and with guiding questions such as:

\footnotetext{
1. Who am I as a writer?

2. To whom do I write?

3. What knowledge and experience do the readers have of this topic?

4. What is the purpose of the text?
} 
Through these questions the students are repeatedly reminded to take into consideration both a writer/speaker and reader/listener perspective in their writings/discussions. Through such instruction the students are acquiring a meta-language which enables classroom discussion about writing and speaking. Further, the assignments often include a set of role-playing situations during which the students are asked to position themselves in the role of a particular writer/speaker or, in the words of Ivanic (1998: 17-21), "assume discoursal identities", for example, as a politician discussing environmental issues or as an investigative journalist reporting on scientific investigations. As a further means of practicing writing as a social act of communication, the students' texts are frequently read/listened to by an authentic audience. For instance, the students have served as guides to younger school children visiting a natural science park. The students have also positioned themselves as (a) textbook authors who were writing a chapter in a natural science textbook for year 8 students, including the writing of a lab/experiment procedural text, and (b) teachers for the same school year (grade 8 students) and their teachers. The above-mentioned examples illustrate how authentic situations are used to practice students' ability to communicate.

Thus, an essential pedagogical principle guiding the T-unit's attempts to increase students'

content-area literacy was the conviction that, in order to comprehend scientific texts, students must first learn how to deconstruct complex, scientific language into their own - simpler, everyday - language. It should be pointed out that the teachers in the T-unit were not aware of Maton's (2013) concept of semantic waves, and built their understanding of content-area literacy on constructivist theories of learning (see e.g. Lave/Wenger 1991; Wenger 1998). Therefore, language activities, such as writing and discussing, play an important role. Writing and speaking are viewed as important mediating tools not only for understanding disciplinary knowledge, but also for communicating through the use of adequate language to classmates as well as other readers/ listeners outside the classroom. Writing and speaking, thus, enable the students to appropriate knowledge through a process which includes explaining information to themselves and to others in their own words.

\section{Data, participants and text analysis}

In this section, I will describe the data that are used in my study and the methods employed for the analysis of the data. The section also includes a brief presentation of the students that participated in the study.

\subsection{Data}

Since I was interested in seeing what kind of natural science texts the students were able to produce after having studied under the T-unit for nearly two years, the data included here were gathered during the spring semester, when the students were involved in a project that focused on researcher(s)' investigations. Project time was scheduled twice per week for a total of four hours. The scientific investigation project lasted six weeks. During this time, I conducted field observations six times (i.e. once a week). Using an ethnographic method (Emerson et al. 2001), my field observations included notes on the language activities, the communication the students had with the researcher(s) behind the scientific investigation in question, and the conversations the students had with their Swedish teacher.

This scientific investigation project challenged the students in several ways. For their writing assignment, the students were required to produce a popular science article on one recent scientific investigation. The students' research for these articles involved the reading of a variety of texts about the topic as well as an interview with one of the researchers (either face-to-face, by mail, or by telephone). The articles were then intended for presentation to their classmates during a seminar. The students were encouraged to use features typical of the popular science article, such as illustrations, explanations, and descriptions of research processes. As in the case of other language activities conducted during project time, writing for the scientific investigation project is viewed 
as a mediating, knowledge-building tool for understanding the disciplinary knowledge involved and for communicating this understanding to classmates and other readers/listeners. Writing (and speaking) were thus viewed as a process in which the students transformed abstract knowledge and language into "an accessible form", while simultaneously appropriating the technical concepts and vocabulary of the natural science discourse.

The scientific investigation project was the most demanding project so far for the students in the T-unit, since it challenged both their reading and writing skills. The science texts they would need to read contain many technical terms and the information is presented in a lexically dense way. When writing, the students most likely would have to synthetize information from various sources (Mateos et al. 2008; Martínez et al. 2015; Newell 2006).

Importantly, the language activities during project time occurred in a steady progression. Thus, the writing of the popular science article was preceded by two assignments, the first of which was reading a popular science article and orally summarizing it to a group of peers, and the second was visiting a local paper, where the students met with journalists who discussed the details of writing articles and creating textual layout, and who then also engaged the students in minor writing activities.

\subsection{Participants and texts}

The natural science class consisted of twenty-two students. A total of fourteen students participated in study. Four pairs of students wrote their projects in English and, hence, due to second-language acquisition considerations, were not included in this study.

Table 1 lists the respective lengths of the students' popular science articles, and provides the number and type of visual elements considered here as well.

$\begin{array}{lr}\text { visual elements } & \text { length } \\ \text { photo (3) } & 957 \\ \text { photo (1), drawing (1) } & 722 \\ \text { photo (1) } & 927 \\ \text { photo (2), text box (1) } & 1205 \\ \text { photo (2), drawing (2), } & \\ \text { table (2) } & 948 \\ \text { photo (1) } & 358\end{array}$

6. Attractive partners shortens the lifespan

photo $(1)$

Table 1. Text title, visual elements, and length of the student texts

As seen from Table 1, the texts treat a diverse range of topics within the natural sciences and also diverge significantly in length from 358 words (text 6) to 1205 words (text 4). The texts also demonstrate a variation in the number and type of visual elements used. It should be pointed out that while the students' texts were originally written in Swedish, the excerpts used here as examples were translated into English.

\subsection{Text analysis}

This study was designed primarily as a linguistic analysis of written student texts. Using Maton's $(2009,2013)$ ideas of cumulative knowledge-building and his concept of semantic waves, the linguistic analysis consisted of an examination of the degree of semantic density and semantic gravity in the students' texts. This analysis was conducted in several phases. In the first phase, a tabu- 
lation of technical terms, including nominalizations/grammatical metaphors and elaborated noun phrases (Halliday 1998) was carried out. The second phase consisted of investigating the extent to which these terms/abstractions were anchored in explanations pertaining to more commonsense knowledge domains, including the use of a less specialized vocabulary. In the third phase, the overall textual structure (e.g. topic sentences, bold words), in combination with the students' use of visual resources, was examined. The visual elements were coded for (a) number and type (e.g. photo, drawing, table, etc.) and (b) degree of abstraction (e.g. a drawing of an object rather than a photo renders a generic, as opposed to a specific, representation of reality, and thus may involve a higher degree of abstraction). In addition, the visual elements were coded for (c) their correlation with the verbal text (e.g. the visual element may represent a contextualization of the verbal text or maintain the strong semantic density of the verbal text) (Guo 2004; Jones 2007; Rowley-Jolivet 2002). The final fourth phase of text analysis consisted of drawing figures of the semantic waves regarding both verbal text and visual elements.

\section{Findings}

The six texts that were analyzed in this study focus on diverse natural science fields, ranging from atomic physics to general medicine. In text 1 , the students describe how a research team was able to photograph electron motion for the first time. Text 2 reports on a study which suggests that a raised level of blood glucose may result in impaired memory function. In text 3 , the students explain a method for monitoring blood glucose level with a biosensor. In text 4, the students present a study aimed to assess the efficacy of retinopathy of prematurity (ROP) in premature infants. Text 5 deals with an investigation of how various types of fungi can be used in the biological control of nematodes. The focus of text 6 is a study that investigates the longevity and reproduction history in a Gotlandic population of collared flycatchers.

The text analysis revealed that each of the six texts presented a distinct semantic profile with regard to, on the one hand, the verbal construction of waves of semantic density and gravity, and, on the other hand, its utilization of visual elements. However, based on the number of different aspects like nominalizations, technical terms and unpacking of abstractions, it was also possible to discern certain commonalities that allowed for the categorization of the texts into three groups:

Group A: High semantic density with waves of contextualization and with a rather high proportion of visual elements playing an important role in the meaning-making processes. The texts in group A are all highly effective as knowledge-building devices.

Group B: Medium to high semantic density with waves of contextualization. Visual elements play a subordinated role in the meaning-making processes. The texts in group B are to a certain degree effective as knowledge-building devices.

Group C: Low semantic density with no need for waves of contextualizing. Visual elements play a subordinated role in the meaning-making processes. The texts in group $\mathrm{C}$ are not effective as knowledge-building devices.

\subsection{Group A (texts 1, 4 and 5)}

In general, it may be said that texts 1,4 and 5 represent a high degree of semantic density given their many clauses involving taxonomic structures of classification and defining and explanatory descriptions with technical terms, all typical of the natural science discourse. As effective knowledge-building tools, texts 1, 4 and 5 also contain downward shifts of unpacking the abstractions through both linguistic features and visual elements.

Text 1 focuses on what would seem the most complex topic of all the students' scientific presentations, namely the successful filming of an electron. As a means of stimulating interest in the content and guiding the reader through the complex research processes described, the student writers employ a number of interpersonal linguistic resources. One example is the introductory sen- 
tences in the first paragraph, where an imperative (italics), an elliptical interrogative (bold), and comment adjuncts (italics and bold) appear:

Imagine a pulse that it is so short that it is related to a second as a second is related to the age of the universe. Difficult to imagine, isn't it? To capture something that is so incredibly short is even more difficult to imagine. But believe it or not somebody has actually succeeded in doing this.

Throughout text 1 , explanatory processes with strong semantic density are found, incorporating nominalizations/grammatical metaphors (italics), elaborated noun phrases (bold) and numeric entries (italics and bold).

\footnotetext{
It takes about 150 attoseconds to circle the nucleus of an atom. In order to capture these rapid movements, extremely short flashes of light are necessary /.../ Yet another precondition for obtaining sharp images is for the process to be repeated in an identical manner which is the case regarding the movement of an electron in a ray of light.
}

The technical abstractions ( $\mathrm{SD}+$ ) are then unpacked by means of a commonsense knowledge domain $\left(\mathrm{SG}^{+}\right)$.

We may compare this with capturing a hummingbird flapping its wings. You then take pictures when
the wings are in the same position, such as at the top.

Importantly, note how the shift in knowledge domain is accompanied by a change in language use: from shifts from an academic register to an informal one that incorporates interpersonal linguistic resources (the personal pronouns $/ w / e$ and $/ y / o u$ ) in the latter sentences. In addition, text 1 includes color photos, one of which illustrates the energy field of an electron and another a hummingbird flapping its wings. These photos are placed near the concluding part of a rather lengthy section that exhibits a high degree of semantic density. Both photos serve as effective contextualizing elements $\left(\mathrm{SG}^{+}\right)$, linking together both the un-commonsense knowledge presented (the filming of an electron) and the representation of this process through an example from an everyday knowledge domain (a hummingbird flapping its wings).

The next student text to be considered, text 4 , begins with a photo, illustrating yellow omega-3 pills against a blue background. The text that accompanies the photo reads: "A scientific study shows that a supplement of omega-3 fatty acids reduces the risk for eye disease." The introduction with its photo provides strong semantic gravity $\left(\mathrm{SG}^{+}\right)$. What follows are text chunks of strong semantic density ( $\mathrm{SD}+)$ that are linguistically realized not only through technical terms/ grammatical metaphors (bold), but also through elaborated noun phrases (italics and bold), and acronymizations (underlined), that is, abbreviations of longer words so typical for the natural science discourse.

Omega-3 belongs to a family of polyunsaturated fatty acids to which Omega- 6 also belongs. / .../ The fatty acids that are particularly important during pregnancy and breastfeeding are DHA (doxosaheraxenooc acid) from the Omega-3 family and AA (arachidonic acid) from the Omega-6 family.

Technical terms and abstractions (bold) of the academic register are unpacked through explanations written in a more informal language (italics). Note also how this unpacking is then followed by an upward shift $(\mathrm{SD}+)$ in which a grammatical metaphor is used to define the scientific term for the process described (bold, last sentence).

Before week 32 the retina is not completely vascularized, which means that there is an area that lacks blood vessels. At a later stage blood vessels may grow, but chances are that these will be pathological, that is sick blood vessels. This entire process is called neo-vascularization.

Text 4, furthermore, includes a detailed and semantically dense description of the five stages of the disease retinopathy $(\mathrm{SD}+)$, a description that is then unpacked $(\mathrm{SG}+)$ through a summary in a visual element, a text box.

Words highlighted in bold demonstrate that a new aspect of the scientific investigation is being introduced, and serve as a means of reader support. 
Annually, approximately 1.000 infants are at risk of developing an eye decease called retinopathy of prematurity (ROP).

Similar to texts 1 and 4, text 5 contains waves of strong semantic density (SD+). Unlike texts 1 and 4, though, text 5 is contextualized through reference to a visit the student writers made to a researcher's laboratory, where they were given the opportunity to conduct a minor research experiment involving the scientific investigation they were to present in their article (which focused on the use of certain fungi in the control of nematodes). The students' experiment (italics) is interwoven in the text with semantically dense information (technical terms in bold) about, for example, DNA sequencing and about the various types of fungi, all written with the use of an academic register typical of the natural science discourse. Because of this textual organization, waves of both strong semantic density (SD+) and semantic gravity ( $\mathrm{SG}^{+}$) are construed.

\footnotetext{
We were allowed to examine two different kinds of fungi Arthrobotrys oligospora and Dactyllella candida. /.../ Predatory fungi catch nematodes with the help of different types of capture means, for example it may be sticky networks, branches, buds or strictly mechanical (sic) means of capture in the form of rings that close around the nematodes. Arthrobotrys oligospora catches nematodes in 3D like rings which the nematodes get stuck in and Dactyllella candida catches nematodes with their buds.
}

Comparison with texts 1 and 4 reveals that text 5 differs regarding the use of visual elements. Whereas texts 1 and 4 incorporate three visual elements each, text 5 contains six visual elements. Some of these semiotic resources also involve a higher degree of abstraction than the visual elements in texts 1 and 4. For example, text 5 includes two tables with numeric entries, detailing the results of the students' research experiment. Numeric entries are generally considered to be a visual element with strong semantic density (Jones 2007). In text 5, the surrounding verbal text explains the tables, thus serving to create waves of stronger semantic gravity.

\footnotetext{
As you see the number of living nematodes have been approximately halved in all four fungi cases, which illustrates that these fungi serve as good predators for the biological control of nematodes.
}

Another visual abstraction in text 5 is a microscopic photo of a nematode caught by a fungus. Text 5 , moreover, includes a photo of one of the students looking into a microscope, thus showing the students' actual involvement in a research experiment. By positioning themselves at the centre of the content, the student writers give their article a strong semantic gravity as well as an interesting insight into the work of a natural science researcher.

The student writers in Group A all acknowledged that their contact with the researcher had been very beneficial. For example, the student writers of text 1 corresponded by mail several times with the researcher who, at some length, explained the various research steps, relying in part on comparative examples from commonsense knowledge domains; these examples are echoed in text 1 . The student writers of text 4 traveled to meet the researcher for an interview outside her laboratory. The student writers of text 5 were invited to the researcher's university laboratory where they were given the opportunity, albeit on a minor scale, to repeat the researcher's experimental study. During this visit, the researcher also showed the students a film pertaining to the scientific investigation, and explained in detail the entire research process.

\subsection{Group B (text 3)}

Similarly to texts 1, 4 and 5, text 3 contains waves of semantic density and gravity. Several explanatory descriptions with technical concepts are used to describe both the technique which makes it possible to construct the biosensor (a device which measures the blood sugar level), and, partly, to describe how the biosensor is injected into the arm, including the function it serves there. The knowledge-building strategy in text 3 is to immediately "translate" the commonsense knowledge (SG+, italics) into an abstraction ( $\mathrm{SD}+$, bold) or vice versa.

They studied how the binding strength, the affinity, varied with temperature and different kinds of sugars. 
Throughout the text, various research processes are clearly described. Clear logical markers between clauses guide the reader through the text (bold and italics).

Fluorescence technique involves that an atom or a molecule is excited. This means that you add a photon, light, to the atom which gives it energy.

However, although it is written in an academic register, text 3 includes fewer peaks of semantic density ( $\mathrm{SD}+$ ) than the texts in Group A. Moreover, text 3 incorporates only one visual element: a photo of a traditional blood sugar measure, using a finger prick to draw blood. A photo displaying the new technique, which would have increased the text's knowledge-building capacities, is not included.

The interview with the researcher was conducted via a telephone conversation where the researcher extensively explained the steps that resulted in the construction of the biosensor.

\subsection{Group $\mathbf{C}($ texts 2 and 6$)$}

Due to their low degree of semantic density, texts 2 and 6 are categorized as Group C-texts. Thus, texts 2 and 6 contain few technical terms. For example, the collared flycatcher, the focus of text 2 , is referenced, not through its Latin name, but with everyday nouns such as male and female and through pronouns (he, she, their).

The females who already at birth have a large body size and were less fat became longlived, explained X X (name of the researcher). She also said that a limited calorie intake at the beginning of life may have prolonged their lives.

As the example suggests, text 2 is largely built through projected clauses (bold), containing information the students obtained during their interview with the researcher. Undoubtedly, the many projected clauses give the text a non-academic language style. As seen in the extract below, text 6 occasionally includes some technical terms ( $\mathrm{SD}+$, bold), which are explained ( $\mathrm{SG}^{+}$, italics), although not to the extent that the text produces semantic waves of knowledge-building.

Episodic memory is what we call short term memory and these are all personal experiences, what you had for breakfast or what date you got married for example.

In addition, texts 2 and 6 each incorporate only one visual element, respectively. In text 2, the visual element is a drawing of the human mind, illustrating the location of hippocampus, thus including abstraction, whereas text 6 contains a photo illustrating a collared flycatcher with a white spot on its forehead. Admittedly, both visual elements heighten the texts' efficacy as learning tools, and, in particular, the drawing in text 6 . It is, however, noteworthy that both texts display a lack of "logical flow," which normally helps the reader follow the transition from one sentence or thought to another.

The interview with the researcher was conducted via telephone conversation. Although the students acknowledged that the researchers' explanations had deepened their understanding of the respective scientific investigation the interview was rather short.

\section{Discussion and conclusion}

This study examined content-area literacy developed as a part of subject integration between the Swedish language and the natural science curriculum. More specifically, it targeted the question of the extent to which the student texts (popular science articles) reporting on scientific investigations fulfilled their function as knowledge-building tools. The answer to this question was sought by investigating the waves of semantic density ( $\mathrm{SD}+$ ) and contextualization/semantic gravity (SG+) in accordance with Maton's (2013) notion of cumulative knowledge-building. This occurs when students, attempting to master academic knowledge replete with technical terms and abstractions, simultaneously consolidate this knowledge/language in explanations that rely upon 
less formal language use. In this study, both verbal texts and visual elements were analyzed, hereby developing the results of previous studies on semantic waves.

The six texts analyzed were categorized into three groups (A, B and C). The findings revealed that each text had a distinct semantic profile, but also that four of the texts (Groups A and B) displayed significant semantic waves of density and gravity, such that these texts would contribute to cumulative knowledge-building. This was primarily true of the texts in Group A where the semantic waves exhibited both strong semantic density and gravity. What further distinguished these three texts from the other texts was the fact that they all incorporated several visual elements, which, taken together, served as effective knowledge-building devices. Placed at "strategic" points in the articles, these visual elements provided a link to the verbal texts, either reinforcing the strong semantic density of the verbal texts, or serving as contextualization tools, providing "explanations"/visualization of an abstract content. This finding is a clear indication of the successful language instruction at the T-unit where the students are continuously engaged in language activities that are taught as communicative social acts, and where the students are constantly reminded to take into consideration a reader/listener during their text production (see Barton et al. 2000). This suggests that the students' participation in the T-unit has shaped a certain collective competence among them that provides essential guidelines for ways of speaking, writing and acting. (Gee 1992; Lave/Wenger 1991; Rogoff 1990).

To a certain degree, all of the texts examined served as knowledge-building tools, but as for the two texts in Group C, their semantic profiles suggest that they only provided superficial oriented learning with no or little use of technical terminology, and no exploration which would have allowed the reader to shape a holistic understanding of the research processes of the respective scientific investigation. As for the text in Group B text, it had a semantic profile that resembled that of the Group A texts. However, the waves of semantic density were fewer. Moreover, the Group B and $\mathrm{C}$ texts contained only one or two visual element(s) each, suggesting that the students did not fully comprehend how visual representations may be used to enhance learning and reader comprehension. (see Kress/van Leeuwen 1996; Maton 2009, 2013).

Several variables may have influenced the outcome of the student texts, one of them being the difference between high-achieving and low-achieving students, which, according to their teacher, probably was one explanation for textual differences. However, in the context of text production, another and highly important variable must also be accounted for, and that is the support each student group received from the researcher. As the results demonstrate, the communication with the respective researchers ranged from rather short telephone conversations to extensive mail correspondences to an invitation from the researcher to spend an afternoon in her laboratory, where she, moreover, engaged the students in an on-going scientific investigation. There is, in fact, a striking correspondence between the knowledge-building the students were able to produce in their texts and to willingness of the researcher to volunteer his/her help to the students. The researchers, thus, served a crucial role as mediators between their scientific investigations, conducted and published in academic contexts, and the students' writing of novice popular science articles within the framework of the natural science discourse. In this respect, project time at the T-unit with its bridging of in and out of school activities became a zone of proximal development where the students, under proper guidance, were able to engage in cumulative knowledge-building. However, the findings also show that some of the students (Group C texts) are in need of further guided instruction in how to organize effective texts for knowledge-building. The findings also illustrate the important role that the integration of verbal text and visual elements played in some of the articles, and how it greatly contributed to enhanced knowledge. An important task for future research is to examine further how students can use various semiotic resources (such as sound, video and image) as tools for the enhancement of effective learning processes in educational settings. 


\section{References}

Applebee, Arthur N. 1996: Curriculum as conversation: Transforming traditions of teaching and learning. Chicago: University of Chicago Press.

Barton, David/Hamilton, Mary/Ivanic, Roz R. 2000: Situated literacies: Reading and writing in context. London/New York: Routledge.

Bernstein, Basil 1996: Pedagogy, symbolic control and identity. Theory, research, Critique. Oxford: Rowman \& Littlefield.

Bezemer, Jeff/Kress, Gunther 2008: Writing in multimodal texts: A social semiotic account of designs. In Written Communication 25(2), 166-195. Doi:10.1177/07410088307313177

Christie, Frances/Derewianka, Beverly 2008: School discourse: Learning to write across the years of schooling. London: Continuum.

Christie, Frances/Macken-Horarik, Mary 2011: Disciplinarity and school subject English. In Christie, Frances/Maton, Karl (eds.), Disciplinarity. Functional linguistics and sociological Perspectives. London/New York: Continuum, 175-196.

Coffin, Caroline 2006: Historical discourse. The language of time, cause, and evaluation. London: Continuum.

Colombi, María Cecilia 2006: Academic language development in Latino students' writing in Spanish. In Schleppegrell, Mary/Colombi, María Cecilia (eds.), Developing advanced literacy in first and second languages. London/ New York: Routledge, 67-86.

Crawford, Teresa/Kelly, Gregory J./Brown, Candice 2000: Ways of knowing beyond facts and laws of science: An ethnographic investigation of student engagement in scientific practices. In Journal of Research in Science Teaching 37, 237-258.

Dyson, Anne H. 1997: Writing superheroes: Contemporary childhood, popular culture, and classroom literacy. New York: Teacher's College Press.

Emerson, Robert M./Fretz, Rachel I./Shaw, Linda L. 2001: Participant observation and fieldnotes. In Atkinson, Paul/ Coffey, Amanda/Delamont, Sara/Lofland, John/Lofland, Lyn (eds.), Handbook of Ethnography. Thousand Oaks, CA: Sage Publications, 356-357.

Fang, Zhihui/Schleppegrell, Mary/Cox, Beverly E. 2006: Understanding the language demands of schooling: Nouns in academic registers. In Journal of Literacy Research 38(3), 247-273.

Gee, James P. 1992: The social mind: Language, ideology and social practice. New York: Bergin \& Garvey.

Gallas, Karen 1994: The language of learning. How children talk, write, dance, draw, and sing their understanding of the world. New York: Teachers College Press.

Guo, Libo 2004: Multimodality in a biology textbook. In O'Halloran, Kay (ed.), Multimodal Discourse analysis: Systemic functional perspectives. London/New York: Continuum 196-219.

Halliday, M. A. K. 1993: Towards a language-based theory of learning. Linguistics and Education 5, 93-116.

Halliday, M. A. K. 1998: Things and relations. Regrammaticising experience as technical knowledge. In Martin, J.R./ Veel, Robert (eds.), Reading science. Critical and functional perspectives on discourses of science. London/New York: Routledge, 185-235.

Ivanic, Roz 1998: Writing and identity: The discoursal construction of identity in academic writing. Amsterdam/Philadelphia: John Benjamins Publishing Company.

Jones, Janet 2007: Multiliteracies for academic purposes: Multimodality in textbook and computer-based learning materials in science at university. In Whittaker, Rachel/McCabe, Anne/ O’Donnell, Mick (eds.), Advances in language and education. London/New York: Continuum, 103-121.

Kilpert, Leigh/Shay, Suellen 2013: Kindling fires: examining the potential for cumulative learning. In Teaching in Higher Education 18(1), 40-52. Doi.org/10.1080/13562517.2012.678326

Kress, Gunther/van Leeuwen, Theo 1996: Reading images: The grammar of visual design. London/New York: Routledge.

Kress, Gunther/Jewitt, Carey/Ogborn, Jon/Tsatsarelis, Charalampos 2001: Multimodal teaching and learning. The rhetorics of the science classroom. London/New York: Continuum.

Langer, Judith A. 1992: Speaking of knowing: Conceptions of understanding in academic disciplines. In Herrington, Anne/Moran, Charles (eds.), Writing, teaching, and learning in the disciplines. New York: Modern Language Association of America.

Langer, Judith A./Applebee, Arthur N. 1987: How writing shapes thinking. Urbana, IL: National Council of Teachers of English. 
Lave, Jean/Wenger, Etienne 1991: Situated learning: Legitimate peripheral participation. Cambridge: Cambridge University Press.

Lemke, Jay L. 1998: Multiplying meaning: Visual and verbal semiotics in scientific texts. In Martin, J.R./Veel, Robert (eds.), Reading science. Critical and functional perspectives on discourses of science. London/New York: Routledge, 87-113.

Lemke, Jay L. 2003: Mathematics in the middle: measure, picture, gesture, sign and word. In Anderson, Myrdene/ Sáenz-Ludlow, Adalira/Zellweger, Shea/Cifarelli, Victor V. (eds.), Educational Perspectives on Mathematics as semiosis: From thinking to interpreting to knowing. Ottawa: Legas, 215-234.

Macken-Horarik, Mary 2004: Interaction with the multi-modal texts: reflections on image and verbiage in art. In Visual Communication 3(1), 5-26. Doi.org/10.1177/1470357204039596.

Macnaught, Lucy/Maton, Karl/Martin, J. R./Matruglio, Erika 2013: Jointly constructing semantic waves: implications for teacher training. In Linguistics and Education, 24(1), 50- 63.

Martínez, Isabel/Mateos, Mar/Martín, Elena/Rijlaarsdam, Gert 2015: Learning history by composing synthesis texts: Effects of an instructional programme on learning, reading and writing processes, and text quality. In Journal of Writing Research 7(2), 275-302. Doi.org/10.17239/JOWR-2015.07.02.03

Martin, J./Rose, D. 2008: Genre relations: mapping culture. Sheffield: Equinox.

Mateos, Mar/Martín, Elena/Villalón, Ruth/Luna, María 2008: Reading and writing to learn in secondary education: online processing activity and written products in summarizing and synthesizing tasks. In Read Write 21, 675-697. Doi 10 1007/s11145-007-9086-6

Maton, Karl 2009: Cumulative and segmented learning: exploring the role of curriculum structures in knowledgebuilding. In British Journal of Sociology of Education, 30(1), 43-57. Doi 10.1080/014256908025114342

Maton, Karl 2011: Theories and things: The semantics of disciplinarity. In Christie, Frances/Maton, Karl (eds.), Disciplinarity: Functional linguistic and sociological perspectives. London/New York: Continuum, 62-84.

Maton, Karl 2013: Making semantic waves: A key to cumulative knowledge-building. In Linguistics and Education, 24(1), 8-22. Doi.org/10.1016/j.linged.2012.11.005

Maun, Ian/Myhill, Debra 2008: Text as design, writers as designers. In English Education 39(2), 5-21. Doi. org/10.1111/j.1754-8845-2005.tb00614.x

Morais, Ana M./Neves, Isabel/Davies, Brian/Daniels, Harry (eds.) 2001: Towards a sociology of pedagogy: The contribution of Basil Bernstein to research. New York: Peter Lang.

Newell, George E. 2006: Writing to learn. How alternative theories of school writing account for student performance. In Charles A. MacArthur/Graham, Steve/Fitzgerald, Jill (eds.), Handbook of writing research. New York: The Guilford Press, 235-247.

Nystrand, Martin 1997: Opening dialogue: Understanding the dynamics of language and Learning in the English classroom. New York: Teachers College Press.

Nystrand, Martin/Duffy, John (eds.) 2003: Towards a rhetoric of everyday life. New directions in research on writing, text, and discourse. Madison, WI: University of Wisconsin Press.

O'Halloran, K. L. 2005: Mathematical discourse - Language, symbolism and visual images.London/New York: Continuum

Richardson, Virginia 2003: Constructivist pedagogy. In Teacher's College Record 105, 1623-1640.

Rogoff, Barbara 1990: Apprenticeship in thinking: Cognitive development in social context. New York: Oxford University Press.

Rowley-Jolivet, Elisabeth 2002: Visual discourse in scientific conference papers: A genrebased study. In English for Specific Purposes 21(1), 19-40.

Schleppegrell, Mary 2004: The language of schooling. A functional linguistic perspective.London/New York: Continuum.

Troia, Gary A./Graham, Steve 2003: Effective writing instruction across the grades: What every educational consult should know. In Journal of Educational and Psychological Consultation (14(1), 75-89.

Ulusoy, Mustafa/Dedeoglu, Hakan 2011: Content area reading and writing: Practices and beliefs. In Australian Journal of Teacher Education 36(4), 1-17. Doi.org/10.14221/ajte.2011v36n4.1

Unsworth, Len 2001: Teaching multiliteracies across the curriculum. Buckingham: Open University Press.

Vacca, Richard T./Vacca, Jo Anne L. 2000: Writing across the curriculum. In Indrisano, Roselmina/Squire, James R. (eds.), Perspectives on writing. Research, theory, and practice. Newark, Delaware: International Reading Association, 214-250. 
Veel, Robert 1997: Learning how to mean - scientifically speaking: Apprenticeship into scientific discourse in the secondary school. In Christie, Frances/Martin, J.R. (eds.), Genre and institutions. Social processes in the workplace and school. London/New York: Continuum, 161-195.

Vygotsky, Lev S. 1978: Mind in society. Cambridge, MA: Harvard University Press (Original work published 1934).

Wenger, Etienne 1998: Community of practice. Learning, meaning and identity.Cambridge: Cambridge University Press.

Whittaker, Rachel/McCabe, Anne/O'Donnell, Mick (eds.) 2007: Advances in language and education. London/New York: Continuum. 